\title{
Beliefs about Development Versus Environmental Tradeoffs in the Puget Sound Region
}

\author{
THOMAS G. SAFFORD, MATTHEW J. CUTLER, \\ MEGAN HENLY, KARMA C. NORMAN, AND PHILLIP S. LEVIN
}

$\mathrm{P}$ olicymakers face difficult decisions as they attempt to balance competing calls for increased development and environmental protection. In the Puget Sound region of Washington State, population growth and the need for housing and energy have brought these types of tradeoffs to the forefront. ${ }^{1}$ Using data from a phone survey of 1,980 residents, researchers from the Carsey Institute and the National Oceanic and Atmospheric Administration (NOAA) Fisheries investigated public perceptions of environmental concerns across Puget Sound. ${ }^{2}$ This fact sheet outlines residents' views about the importance of environmental protection as well as their opinions about energy development, protection of wild salmon, and land use regulation.

We asked respondents whether they believed it was more important to protect the environment at the risk of curbing economic growth or to promote economic growth even if the environment suffers to some extent. Most residents support environmental protection. Nearly three-fourths (74 percent) indicated that protecting the environment, even at the risk of curbing growth, was more important. However, additional survey questions illustrate key regional differences in patterns of support for specific proposals.

Among residents, 82 percent thought increased use of renewable energy, such as wind and solar, should be a higher priority than expanded drilling for oil for the future of the country (see Figures 1A and 1B). Support for more renewable

FIGURE 1A. PRIORITY: EXPAND DRILLING FOR OIL OR INCREASE USE OF RENEWABLE ENERGY?

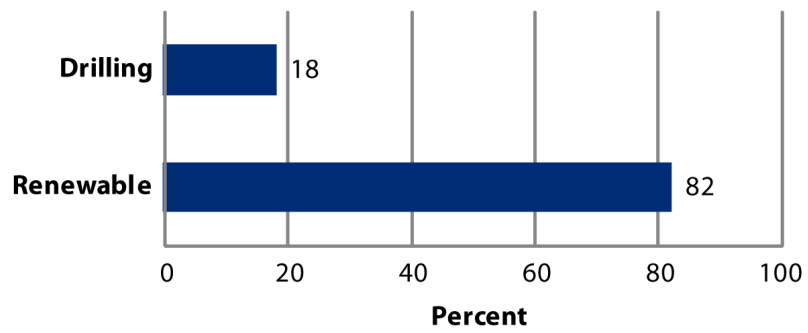

\section{Key Findings}

- Seventy-four percent of Puget Sound residents believe that protecting the environment should be a priority even if it means limiting economic growth.

- The majority of residents favor both increased use of renewable energy ( 82 percent) and protecting wild salmon ( 75 percent).

- Residents are more divided about curbing development, with those from rural areas being more apt to prioritize protecting private property rights over regulating land use.

energy was prevalent across Puget Sound, but larger percentages of urban than rural residents believed this should be prioritized over further drilling for oil. Less enthusiasm among rural residents may reflect debates within rural communities about the on-the-ground social, economic, and environmental implications of alternative energy development. Expansion of wind, solar, and biomass energy production is more likely to occur in rural areas. ${ }^{3}$

Salmon are iconic to Washington State. Therefore, it is not surprising that the vast majority of residents view protecting wild salmon as imperative (see Figures $2 \mathrm{~A}$ and $2 \mathrm{~B}$ ).

FIgURE 1B. "INCREASE USE OF RENEWABLE ENERGY" BY PLACE OF RESIDENCE

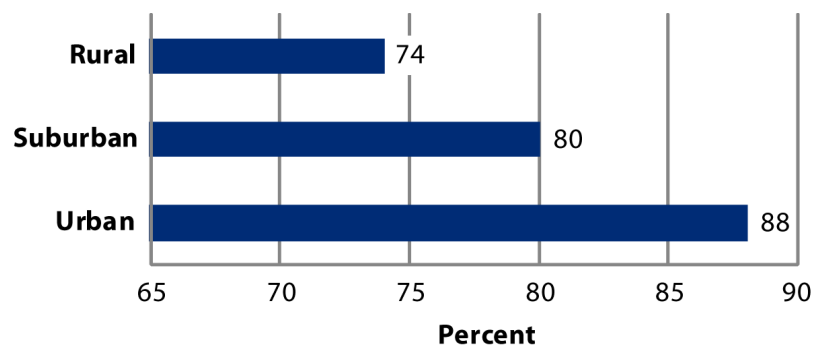

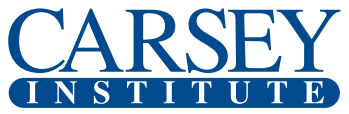
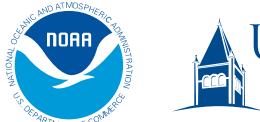

To read more about this project, go to:

http://carseyinstitute.unh.edu/cera/puget-sound 
FIgURE 2A. ENSURING AVAILABILITY OF SALMON FOR FISHING OR PROTECT WILD SALMON POPULATIONS

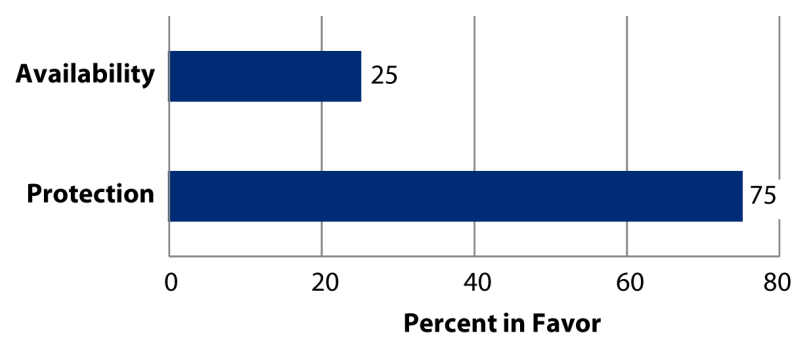

Figure 2B. "Protect WiLD SALMON POPULATIONS" By PLACE OF RESIDENCE

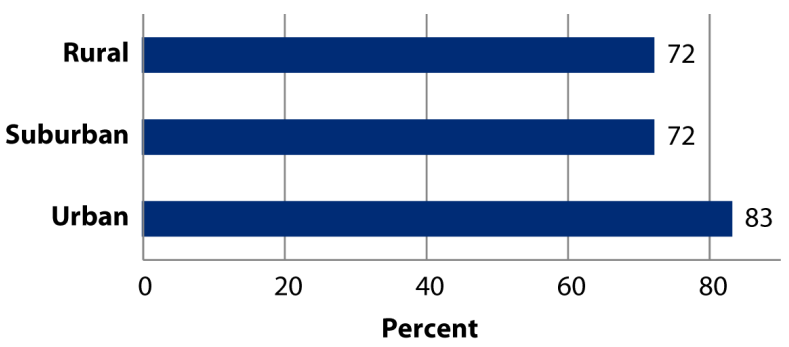

When asked whether ensuring the availability of salmon for recreational and commercial fishing or protecting wild salmon populations was more important for their community, a large majority, 75 percent, indicated protecting wild salmon was more important even if it reduces the number of fish available to fishermen. Although we found some regional variation in these views, the differences were less pronounced than those related to energy. The uniformity of these results may reflect the shared cultural importance of salmon across Puget Sound.

Puget Sound residents appear to value the environment, but they are more split over the role of government in mediating individual interests versus the common good. We asked respondents whether they believed property owners should be able to do what they want with their land or whether government should be able to regulate land use for the public good (see Figures $3 \mathrm{~A}$ and $3 \mathrm{~B}$ ). Less than one-half ( 45 percent) believed the government should regulate land use for the common good. The remaining respondents either favored individual rights (32 percent) or were uncertain (23 percent). Place of residence significantly influenced opinions, with rural residents more likely to prioritize property rights. ${ }^{4}$ Property owners in rural and suburban areas are more apt to be affected by increased landuse regulation. Therefore, their greater resistance to government regulating land-use makes sense.

These place-related differences in support for the environmental protection and land use regulations provide a cautionary note for regional planners. Integrating social data and analysis into broader scientific information about environmental issues may help policymakers identify approaches that strike the necessary balance between the economic needs of communities and those of the Puget Sound environment.
Figure 3A. SHOULD PROPERTY OWNERS BE ABLE TO DO WHAT THEY WANT WITH THEIR LAND OR SHOULD GOVERNMENT REGULATE LAND USE FOR THE COMMON GOOD.

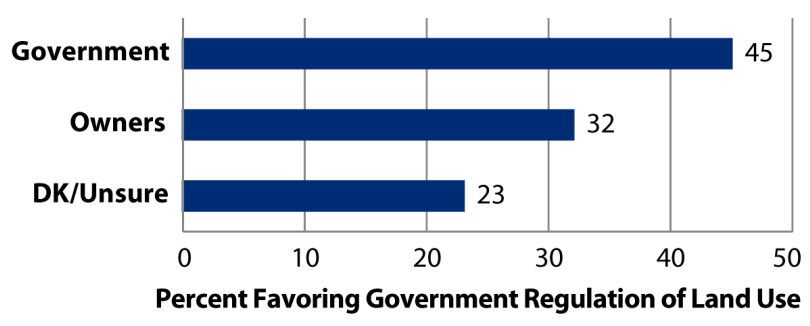

Figure 3B. "Property OWNERS SHOULD Be AbLE TO DO WHAT THEY WANT WITH LAND" BY PLACE OF RESIDENCE

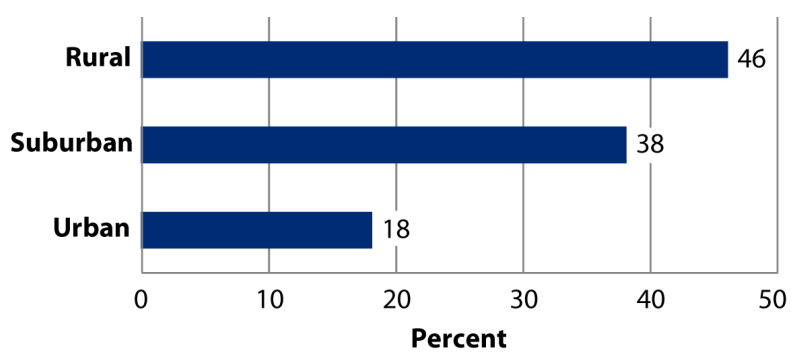

E N D N O T E S

1. Puget Sound Partnership (PSP), "Puget Sound Action Agenda: Protecting and Restoring the Puget Sound Ecosystem by 2020" (Olympia, WA: PSP, 2008).

2. The UNH Survey Center administered a random digit dial phone survey to 1,980 residents of King, Kitsap, Mason, Pierce, Skagit, and Whatcom counties in January and February 2012 and July and August 2012. Data were weighted to make slight adjustments for non-response by age, race, and sex and to adjust for known effects of sampling design (for example, county population and household size).

3. R. D. Kahn, "Siting Struggles: The Unique Challenge of Permitting Renewable Energy Power Plants," The Electricity Journal, vol. 13, no. 2 (2000): 21-33.

4. Analysis of variance with a Scheffe posthoc test comparing averages within each type of community demonstrates statistical significance at 99 percent $(\mathrm{p}<0.01)$.

\section{A C K N O W L E D G MEN T S}

The authors appreciate the funding support of the National Oceanic and Atmospheric Administration (NOAA) Fisheries and the U.S. Environmental Protection Agency, as well as the support of the UNH Survey Center and the Carsey Institute.

\section{ABOUT THE AUTHORS}

Thomas Safford is an assistant professor of sociology at the University of New Hampshire and a faculty fellow at the Carsey Institute (tom.safford@unh.edu); Matthew Cutler is a Ph.D. student in sociology at the University of New Hampshire (mjcutler@unh.edu); Megan Henly is a Ph.D. student in sociology at the University of New Hampshire (megan.henly@unh.edu); Karma Norman is a social scientist with NOAA Fisheries in Seattle (karma.norman@noaa.gov); and Phillip Levin is an ecologist and senior scientist with NOAA Fisheries in Seattle (phil.levin@noaa.gov). 